\title{
Progressive Particle Swarm Optimization Algorithm for Solving Reactive Power Problem
}

\author{
Kanagasabai Lenin ${ }^{\mathrm{a}, 1^{*}}$, Bhumanapally Ravindhranath Reddy ${ }^{\mathrm{b}, 2}$, Munagala Surya Kalavathi ${ }^{\mathrm{c}, 3}$ \\ ${ }^{a}$ Research Scholar, JNTU, Hyderabad 500 085, India \\ ${ }^{b}$ Deputy executive engineer, JNTU, Hyderabad 500 085, India \\ ${ }^{c}$ Professor in Department of Electrical and Electronics Engineering, JNTU, Hyderabad 500 085, India \\ Igklenin@gmail.com*,2bumanapalli-brreddy@yahoo.co.in,3munagala12@yahoo.co.in
}

Article history:

Received September 29, 2015

Revised November 11, 2015

Accepted November 30, 2015

Keywords:

Particle swarm

Progressive

Pbest

Gbest

Optimization

Optimal reactive power

Transmission loss
In this paper a Progressive particle swarm optimization algorithm (PPS) is used to solve optimal reactive power problem. A Particle Swarm Optimization algorithm maintains a swarm of particles, where each particle has position vector and velocity vector which represents the potential solutions of the particles. These vectors are modernized from the information of global best (Gbest) and personal best (Pbest) of the swarm. All particles move in the search space to obtain optimal solution. In this paper a new concept is introduced of calculating the velocity of the particles with the help of Euclidian Distance conception. This new-fangled perception helps in finding whether the particle is closer to Pbest or Gbest and updates the velocity equation consequently. By this we plan to perk up the performance in terms of the optimal solution within a rational number of generations. The projected PPS has been tested on standard IEEE 30 bus test system and simulation results show clearly the better performance of the proposed algorithm in reducing the real power loss with control variables are within the limits.

Copyright $(\underset{2}{2015}$ International Journal of Advances in Intelligent Informatics. All rights reserved.

\section{Introduction}

Various algorithms utilized to solve the reactive power problem.Various numerical methods like the gradient method [1-2], Newton method [3] and linear programming [4-7] have been utilized to solve the optimal reactive power dispatch problem. The problem of voltage stability and collapse play a key role in power system planning and operation [8].Evolutionary algorithms such as genetic algorithm have been already utilized to solve the reactive power flow problem [9-11]. In [12], Hybrid differential evolution algorithm is utilized to improve the voltage stability index. In [13] Biogeography Based algorithm have been used to solve the reactive power dispatch problem. In [14], a fuzzy based methodology is used to solve the optimal reactive power scheduling method. In [15], an improved evolutionary programming is used to solve the optimal reactive power dispatch problem. In [16], the optimal reactive power flow problem is solved by integrating a genetic algorithm with a nonlinear interior point method. In [17], a pattern algorithm is used to solve ac-dc optimal reactive power flow model with the generator capability limits. In [18], F. Capitanescu proposes a two-step approach to evaluate Reactive power reserves with respect to operating constraints and voltage stability. In [19], a programming based approach is used to solve the optimal reactive power dispatch problem. In [20], A. Kargarian et al present a probabilistic algorithm for optimal reactive power provision in hybrid electricity markets with uncertain loads. This paper proposes Progressive particle swarm optimization [21-24] algorithm (PPS) to solve reactive power dispatch problem. In this paper a new concept is introduced of calculating the velocity of the particles with the help of Euclidian Distance conception. This new-fangled perception helps in finding whether the particle is closer to Pbest or Gbest and updates the velocity equation consequently. The proposed PPS has been evaluated on standard IEEE 30 bus test system. The simulation results show that our proposed approach outperforms all the entitled reported algorithms in minimization of real power loss. 


\section{Ease of Use}

\section{A. Active power loss}

The objective of the reactive power dispatch is to minimize the active power loss (PL) in the transmission network, which can be mathematically described as in (1).

$$
F=P L=\sum_{k \in N b r} g_{k}\left(V_{i}^{2}+V_{j}^{2}-2 V_{i} V_{j} \cos \theta_{i j}\right)
$$

Where $g_{k}$ is the conductance of branch between nodes $i$ and $j, \mathrm{Nbr}$ is the total number of transmission lines in power systems.

\section{B. Voltage profile improvement}

For minimizing the voltage deviation in PQ buses, the objective function becomes (2).

$$
F=P L+\omega_{v} \times V D
$$

Where $\omega_{\mathrm{v}}$ is a weighting factor of voltage deviation.

VD is the voltage deviation given by (3).

$$
V D=\sum_{i=1}^{N p q}\left|V_{i}-1\right|
$$

\section{Equality Constraint}

The equality constraint of the ORPD problem is represented by the power balance equation, where the total power generation $\left(\mathrm{P}_{\mathrm{G}}\right)$ must cover the total power demand $\left(\mathrm{P}_{\mathrm{D}}\right)$ and the power losses $\left(\mathrm{P}_{\mathrm{L}}\right)$ as in (4).

$$
P_{G}=P_{D}+P_{L}
$$

\section{Inequality Constraints}

The inequality constraints imitate the limits on components in the power system as well as the limits created to ensure system security. Upper and lower bounds on the active power of slack bus, and reactive power of generators given in (5) and (6).

$$
\begin{aligned}
& P_{\text {gslack }}^{\min } \leq P_{\text {gslack }} \leq P_{\text {gslack }}^{\text {max }} \\
& Q_{g i}^{\min } \leq Q_{g i} \leq Q_{g i}^{\max }, i \in N_{g}
\end{aligned}
$$

Upper and lower bounds on the bus voltage magnitudes given in (7).

$$
V_{i}^{\min } \leq V_{i} \leq V_{i}^{\max }, i \in N
$$

Upper and lower bounds on the transformers tap ratios given in (8).

$$
T_{i}^{\min } \leq T_{i} \leq T_{i}^{\max }, i \in N_{T}
$$

Upper and lower bounds on the compensators reactive powers given in (9).

$$
Q_{c}^{\min } \leq Q_{c} \leq Q_{C}^{\max }, i \in N_{C}
$$

Where $\mathrm{N}$ is the total number of buses, $\mathrm{N}_{\mathrm{T}}$ is the total number of Transformers, $\mathrm{N}_{\mathrm{c}}$ is the total number of shunt reactive compensators.

\section{Particle Swarm Optimization}

Inspired by the social cooperative and competitive behaviour of bird flocking and fish schooling, Kennedy and Eberhart [21,22] proposed a new optimization technique called particle swarm 
optimization (PSO). The motivation behind this method was based on the simulation of animal social behaviours like fish schooling, bird flocking and many more. PSO has drawn widespread attention in the last decades. Like other evolutionary algorithms particle swarm algorithm starts with the random initialization of a population of individuals in the search space. But in PSO there is no direct recombination of genetic material between individuals during the search. Therefore, it finds the global best solution by simply adjusting the trajectory of each individual during the search. This algorithm works on the social behaviour of particles in the swarm. Therefore, it finds the global best solution by simply adjusting the trajectory of each individual toward its own best location and toward the best particle of entire swarm at each generation (time step) [21,22]. In simple language, the particles are flown through a multidimensional search space, where the position of each particle is adjusted according to its own experience and that of its neighbours, following two components are evaluated:

1) Position of the particle $\left(X_{\text {id }}\right)$

2) Velocity of the particle $\left(V_{\text {id }}\right)$

To calculate these two modules of PSO, a swarm of particles having position vector and velocity vector of the ith particle in the d-dimension search space can be represented as $X_{i}=\left(x_{i 1}, x_{i 2}, x_{i 3}, \ldots\right.$, $\left.\mathrm{x}_{\mathrm{id}}\right)$ and $\mathrm{V}_{\mathrm{i}}=\left(\mathrm{v}_{\mathrm{i} 1}, \mathrm{v}_{\mathrm{i} 2}, \mathrm{v}_{\mathrm{i} 3}, \ldots, \mathrm{v}_{\mathrm{id}}\right)$ respectively. By using fitness function, can be unimodal or multimodal in nature suppose the best position of each particle i.e., best fitness value obtained by that particle at time $t$ is Pbest $=\left(p_{i 1}, p_{i 2}, p_{i 3}, \ldots, p_{i d}\right)$, and the fittest particle found till now at time $t$ is Gbest $=\left(p_{\mathrm{g} 1}, \mathrm{p}_{\mathrm{g} 2}, \mathrm{p}_{\mathrm{g} 3}, \ldots, \mathrm{p}_{\mathrm{gd}}\right)$. Then, for calculating the new velocities and the positions of the particles for next fitness evaluation following equations as in (10) and (11).

$$
\begin{aligned}
& V_{i d}=V_{i d}+C_{1} * \operatorname{rand}_{1}(\cdot) *\left(P_{i d}-X_{i d}\right)+C_{2} \operatorname{rand}_{2}(\cdot) *\left(P_{g d}-X_{i d}\right) \\
& X_{i d}=X_{i d}+V_{i d}
\end{aligned}
$$

Where $c_{1}$ and $c_{2}$ are positive acceleration constants used to scale the contribution of cognitive and social components respectively and rand 1 and rand 2 are two separately generated uniformly distributed random numbers in range $[0,1]$.

The first part of (10) represents the previous velocity, which provides the necessary momentum for particles to roam across the search space. The second part, known as the cognitive component, represents the personal thinking of each particle. The cognitive component encourages the particles to move toward their own best positions found so far. The third part is known as the social component, which represents the collaborative effect of the particles, in finding the global optimal solution. The social component always pulls the particles toward the global best particle found so far. Initially, a population of particles is generated with random positions, and then random velocities are assigned to each particle. The fitness of each particle is then evaluated according to a user defined objective function. At each generation, the velocity of each particle is calculated according to (10) and the position for the next function evaluation is updated according to (11).Each time if a particle finds a better position than the previously found best position, its location is stored in memory. Generally, a maximum velocity $\left(\mathrm{V}_{\max }\right)$ for each modulus of the velocity vector of the particles $\left(\mathrm{V}_{\mathrm{id}}\right)$ is defined in order to Control excessive roaming of particles outside the user defined search space. Whenever a $V_{\text {id }}$ exceeds the defined limit, its velocity is set to $\mathrm{V}_{\max }$.

\section{Progressive particle swarm optimization algorithm}

In this paper we are using a new concept of closeness based evaluation on the swarm. As we know heuristic approaches have not necessarily been proven to produce the global minimum with every trial or to be applicable in all cases. Rather, they have been demonstrated to work well in general. Since, PSO is population based heuristic search and the speed of population based search heuristic can be measured in iterations, function evaluations or real time. Since, each particle evaluates its function value at each iteration the number of function evaluations conducted per iteration is equal to the number of search agents. Function evaluation seems to be most popular measure. Real time is not generally used since the time required to run simulation on one computer might not equal the time required on another computer, making real time comparison from paper to paper is practically 
impossible. The optimization problem is then to find values of the variables that minimizes or maximizes the objective function while satisfying the constraints.

Generally in population based optimization method, it is desirable to encourage the individuals to wander through the entire search space without clustering around the local optima, during the early stages of the optimization. On the other side, during the latter stages, it is very important to enhance convergence toward the global optima, to find optimum solution efficiently. Considering these concerns, in this paper we propose new concept of calculating the distance among the particles which helps in determining the closeness towards Gbest or Pbest, named as closeness based method. This concept is applied with HPSO (Hierarchical Particle Swarm Optimizer) -TVAC (Time-Varying Acceleration Coefficients) which yields a new algorithm termed as closeness based HPSO with TVAC, which uses TVAC as new parameter strategy for the PSO concept and on the basis of Euclidian distance between the particle and Pbest and particle and Gbest elements of the swarm are accelerating towards the optimal solution [23]. This concept depicts the problem of minimization clearly. Firstly, in TVAC like ratnaweera et al [24] has proposed in his work, we reduce the cognitive component and increase the social component by changing the acceleration coefficient $\mathrm{c}_{1}$ and $\mathrm{c}_{2}$ with time. This is known as PSO-TVAC method.

Secondly, Kennedy et al [21] proposed a version of PSO without the velocity of previous iteration. Later they concluded that since this version is very simple, it is ineffective in finding global optimal for complex problems. To overcome this problem ratnaweera et al [24] proposed HPSO to provide the required momentum for particles to find global optimum solution in the absence of previous velocity term in (10). Lastly, our new concept is introduced here to enhance the performance furthermore which yields good results. The closeness is calculated with the help of Euclidian distance among the particles. If the particle is more closer to Gbest then move that particle toward Gbest by reducing the cognitive factor $\mathrm{c} 1$ and increasing the social factor $\mathrm{c} 2$ by specific value in velocity update equation (10) else vice-versa. Hence, a significant improvement of performance is observed with this new closeness based HPSO with TVAC method and also proves its acceptance for minimization problem of optimization.

The PPS algorithm for solving reactive power problem:

1. Generate random population of particle with random position and velocity in search space.

2. Set the parameters of the algorithm as:
$\mathrm{C}_{1 \text { min }}=0.5$
$\mathrm{C}_{1 \text { max }}=2.5$
$\mathrm{C}_{2}{ }_{\text {min }}=0.5$
$\mathrm{C}_{2}$ max $=2.5$
$\mathrm{W}_{\min }=0.4$
$\mathrm{W}_{\max }=0.9$
$\mathrm{C}_{1}=2.5$
$\mathrm{C}_{2}=0.5$

3. Find initial function values of the swarm by using fitness function.

4. Find the local best (Pbest) position of ith particle.

5. Find the global best (which is best among personal best (Pbest)) position of the swarm, i.e., Gbest.

6. For $\mathrm{i}=1$ to $\mathrm{I}_{\max }$, calculate the varying coefficient factors i.e., $\mathrm{C}_{1_{-} \mathrm{var}}, \mathrm{C}_{2_{-} \text {var }}$ and $\mathrm{W}_{-}$var to upgrade the acceleration coefficients and inertia weight.

7. Calculate the Euclidian distance for each particle between

a. Particle's and Gbest's position $\left(\mathrm{D}_{\mathrm{XG}}\right)$.

b. Particle's and Pbest's position $\left(\mathrm{D}_{\mathrm{XP}}\right)$.

8. Update the value of inertia weight by $\mathrm{W}=\mathrm{W}-\mathrm{W}_{-}$var

9. Check if $\mathrm{D}_{\mathrm{XG}}<\mathrm{D}_{\mathrm{XP}}$

Then update $\mathrm{C}_{1}=\mathrm{C}_{1}-\mathrm{C}_{1}$ var

$$
\begin{aligned}
& \mathrm{C}_{2}=\mathrm{C}_{2}+\mathrm{C}_{2 \text { _var }} \\
& \text { Else } \mathrm{C}_{1}=\mathrm{C}_{1}+\mathrm{C}_{1 \_\mathrm{var}} \\
& \mathrm{C}_{2}=\mathrm{C}_{2}-\mathrm{C}_{2 \text { _var }}
\end{aligned}
$$


10. Update the velocity $\left(\mathrm{V}_{\mathrm{id}}\right)$ of each particle by the velocity vector equation: $V_{i d}=V_{i d}+C_{1}$ * $\operatorname{rand}_{1}(\cdot) *\left(P_{i d}-X_{i d}\right)+C_{2} \operatorname{rand}_{2}(\cdot) *\left(P_{g d}-X_{i d}\right)$

11. Update the position $X_{\text {id }}$ of each particle by position vector equation: $X_{i d}=X_{i d}+V_{i d}$

12. Update the velocity and position of Gbest particle.

13. Repeat step 3 to step 13 until termination criteria is met (maximum number of iteration).

14. Stop

\section{Simulation Results}

Validity of the proposed PPS algorithm has been verified in IEEE 30-bus, 41 branch system. It has 6 generator-bus voltage magnitudes, 4 transformer-tap settings, and 2 bus shunt reactive compensators. Bus 1 is slack bus and 2, 5, 8,11 and 13 are taken as PV generator buses and the rest are PQ load buses. Preliminary control variables limits are listed in Table 1 . The power limits generators buses are represented in Table 2. Generators buses (PV) 2,5,8,11,13 and slack bus is 1 . Table 3 shows the proposed approach succeeds in keeping the control variables within limits. Table 4 summarizes the results of the optimal solution obtained by various methods. Table 4 clearly shows the good performance of the proposed algorithm in reducing the real power loss.

Table 1. Preliminary Variable Limits (PU)

\begin{tabular}{cccc}
\hline Variables & $\begin{array}{c}\text { Min. } \\
\text { Value }\end{array}$ & $\begin{array}{c}\text { Max. } \\
\text { Value }\end{array}$ & Type \\
\hline Generator Bus & 0.92 & 1.12 & Continuous \\
\hline Load Bus & 0.94 & 1.04 & Continuous \\
\hline Transformer-Tap & 0.94 & 1.04 & Discrete \\
\hline Shunt Reactive Compensator & -0.11 & 0.30 & Discrete \\
\hline
\end{tabular}

Table 2. Generators Power Limits

\begin{tabular}{ccccc}
\hline Bus & Pg. & Pgmin & Pgmax & Qgmin \\
\hline 1 & 98.00 & 51 & 202 & -21 \\
\hline 2 & 81.00 & 22 & 81 & -21 \\
\hline 5 & 53.00 & 16 & 53 & -16 \\
\hline 8 & 21.00 & 11 & 34 & -16 \\
\hline 11 & 21.00 & 11 & 29 & -11 \\
\hline 13 & 21.00 & 13 & 41 & -16 \\
\hline
\end{tabular}

Table 3. Values of Control Variables after Optimization

\begin{tabular}{cc}
\hline $\begin{array}{c}\text { Control } \\
\text { Variables }\end{array}$ & PPS \\
\hline $\mathrm{V} 1$ & 1.0689 \\
\hline $\mathrm{V} 2$ & 1.0527 \\
\hline $\mathrm{V} 5$ & 1.0324 \\
\hline $\mathrm{V} 8$ & 1.0426 \\
\hline $\mathrm{V} 11$ & 1.0824 \\
\hline $\mathrm{V} 13$ & 1.0622 \\
\hline $\mathrm{T} 4,12$ & 0.00 \\
\hline $\mathrm{T} 6,9$ & 0.01 \\
\hline $\mathrm{T} 6,10$ & 0.90 \\
\hline $\mathrm{T} 28,27$ & 0.91 \\
\hline $\mathrm{Q} 10$ & 0.11 \\
\hline $\mathrm{Q} 24$ & 0.11 \\
\hline Real power loss & 4.2790 \\
\hline Voltage deviation & 0.9037
\end{tabular}


Table 4. Comparison Results

\begin{tabular}{cc}
\hline Methods & Real power loss (MW) \\
\hline SGA (25) & 4.98 \\
\hline PSO (26) & 4.9262 \\
\hline LP (27) & 5.988 \\
\hline EP (27) & 4.963 \\
\hline CGA (27) & 4.980 \\
\hline AGA (27) & 4.926 \\
\hline CLPSO (27) & 4.7208 \\
\hline HSA (28) & 4.7624 \\
\hline BB-BC (29) & 4.690 \\
\hline PPS & 4.2790 \\
\hline
\end{tabular}

\section{Conclusion}

In this paper, Progressive particle swarm optimization algorithm (PPS) has been effectively implemented to solve Optimal Reactive Power Dispatch problem. The proposed algorithm has been tested on the standard IEEE 30 bus system. Simulation results show the robustness of proposed Progressive particle swarm optimization algorithm (PPS) method for providing better optimal solution in decreasing the real power loss. The control variables obtained after the optimization by Progressive particle swarm optimization algorithm (PPS) is within the limits.

\section{References}

[1] O.Alsac,and B. Scott, “Optimal load flow with steady state security”,IEEE Transaction. PAS -1973, pp. 745-751.

[2] Lee K Y ,Paru Y M , Oritz J L -A united approach to optimal real and reactive power dispatch , IEEE Transactions on power Apparatus and systems 1985: PAS-104 : 1147-1153

[3] A.Monticelli , M .V.F Pereira ,and S. Granville , "Security constrained optimal power flow with post contingency corrective rescheduling", IEEE Transactions on Power Systems :PWRS-2, No. 1, pp.175182., 1987 .

[4] Deeb N ,Shahidehpur S.M ,Linear reactive power optimization in a large power network using the decomposition approach. IEEE Transactions on power system 1990: 5(2) : 428-435

[5] E. Hobson,'Network consrained reactive power control using linear programming, ' IEEE Transactions on power systems PAS -99 (4), pp 868=877, 1980

[6] K.Y Lee,Y.M Park, and J.L Oritz, "Fuel -cost optimization for both real and reactive power dispatches" , IEE Proc; 131C,(3), pp.85-93.

[7] M.K. Mangoli, and K.Y. Lee, "Optimal real and reactive power control using linear programming", Electr.Power Syst.Res, Vol.26, pp.1-10,1993.

[8] C.A. Canizares , A.C.Z.de Souza and V.H. Quintana, "Comparison of performance indices for detection of proximity to voltage collapse," vol. 11. no.3 , pp.1441-1450, Aug 1996 .

[9] S.R.Paranjothi , and K.Anburaja, "Optimal power flow using refined genetic algorithm", Electr.Power Compon.Syst, Vol. 30, 1055-1063,2002.

[10]D. Devaraj, and B. Yeganarayana, "Genetic algorithm based optimal power flow for security enhancement", IEE proc-Generation.Transmission and. Distribution; 152, 6 November 2005.

[11]A. Berizzi, C. Bovo, M. Merlo, and M. Delfanti, "A ga approach to compare orpf objective functions including secondary voltage regulation," Electric Power Systems Research, vol. 84, no. 1, pp. 187 - 194, 2012.

[12]C.-F. Yang, G. G. Lai, C.-H. Lee, C.-T. Su, and G. W. Chang, "Optimal setting of reactive compensation devices with an improved voltage stability index for voltage stability enhancement," International Journal of Electrical Power and Energy Systems, vol. 37, no. 1, pp. 50 - 57, 2012.

[13]P. Roy, S. Ghoshal, and S. Thakur, "Optimal var control for improvements in voltage profiles and for real power loss minimization using biogeography based optimization," International Journal of Electrical Power and Energy Systems, vol. 43, no. 1, pp. 830 - 838, 2012. 
[14]B. Venkatesh, G. Sadasivam, and M. Khan, "A new optimal reactive power scheduling method for loss minimization and voltage stability margin maximization using successive multi-objective fuzzy lp technique,” IEEE Transactions on Power Systems, vol. 15, no. 2, pp. 844 - 851, may 2000.

[15] W. Yan, S. Lu, and D. Yu, “A novel optimal reactive power dispatch method based on an improved hybrid evolutionary programming technique," IEEE Transactions on Power Systems, vol. 19, no. 2, pp. 913 918, may 2004.

[16] W. Yan, F. Liu, C. Chung, and K. Wong, "A hybrid genetic algorithminterior point method for optimal reactive power flow," IEEE Transactions on Power Systems, vol. 21, no. 3, pp. 1163 -1169, aug. 2006.

[17] J. Yu, W. Yan, W. Li, C. Chung, and K. Wong, “An unfixed piecewiseoptimal reactive power-flow model and its algorithm for ac-dc systems," IEEE Transactions on Power Systems, vol. 23, no. 1, pp. 170 -176, feb. 2008.

[18]F. Capitanescu, "Assessing reactive power reserves with respect to operating constraints and voltage stability," IEEE Transactions on Power Systems, vol. 26, no. 4, pp. 2224-2234, nov. 2011.

[19]Z. Hu, X. Wang, and G. Taylor, "Stochastic optimal reactive power dispatch: Formulation and solution method," International Journal of Electrical Power and Energy Systems, vol. 32, no. 6, pp. 615 - 621, 2010 .

[20]A. Kargarian, M. Raoofat, and M. Mohammadi, "Probabilistic reactive power procurement in hybrid electricity markets with uncertain loads," Electric Power Systems Research, vol. 82, no. 1, pp. $68-80$, 2012.

[21] R. Eberhart and J. Kennedy, A new optimizer using particle swarm theory, in proc. 6th Int. Symp. Micro Machine Human Sci., 1995, pp.39-43.

[22]Kennedy, J.; Eberhart, R. (1995). Particle Swarm Optimization. Proceedings of IEEE International Conference on Neural Networks IV. pp. 1942-1948.

[23] S. Yang and C. Li (Dec. 2010), A clustering particle swarm optimizer for locating and tracking multiple optima in dynamic environments, IEEE Trans. Evol. Comput., vol. 14, no. 6, pp. 959-974.

[24]A. Ratnaweera, S. K. Halgamuge, and H. C. Watson (Jun. 2004), Self-organizing hierarchical particle swarm optimizer with time-varying acceleration coefficients, IEEE Trans. Evol. Comput., vol. 8, no. 3, pp. 240-255.

[25]Q.H. Wu, Y.J.Cao, and J.Y. Wen. Optimal reactive power dispatch using an adaptive genetic algorithm. Int. J. Elect. Power Energy Syst. Vol 20. Pp. 563-569; Aug 1998.

[26]B. Zhao, C. X. Guo, and Y.J. CAO. Multiagent-based particle swarm optimization approach for optimal reactive power dispatch. IEEE Trans. Power Syst. Vol. 20, no. 2, pp. 1070-1078, May 2005.

[27] Mahadevan. K, Kannan P. S. "Comprehensive Learning Particle Swarm Optimization for Reactive Power Dispatch”, Applied Soft Computing, Vol. 10, No. 2, pp. 641-52, March 2010.

[28] A.H. Khazali, M. Kalantar, "Optimal Reactive Power Dispatch based on Harmony Search Algorithm", Electrical Power and Energy Systems, Vol. 33, No. 3, pp. 684-692, March 2011.

[29] S. Sakthivel, M. Gayathri, V. Manimozhi, “A Nature Inspired Optimization Algorithm for Reactive Power Control in a Power System”, International Journal of Recent Technology and Engineering (IJRTE) ,pp2933 Volume-2, Issue-1, March 2013. 